\title{
College Students' Mental Health is Influenced to be Worse during the COVID-19 Pandemic
}

\author{
Shuchen Jin \\ Michigan State University, East Lansing, MI 48823, United States \\ jinshuch@msu.edu

\begin{abstract}
Mental health is an important aspect that should be emphasized during this period of the pandemic, and some studies have shown that the mental health problems of college students have worsened after the pandemic. This will affect their study hours, sleep, and any other aspects of life for college students. The hypothesis is that the mental health of college students has become worse than before due to the impact of the pandemic in three aspects: daily study hours, daily sleep hours, and the impact of news reports. This article conducted a survey of 727 college students and found that they spent less time studying and more time sleeping. Meanwhile, news reports have also affected their mood to some extent.
\end{abstract}

Keywords: college students, mental health, COVID-19 pandemic, study hours, sleep hours, news reports

\section{INTRODUCTION}

Since the first corona virus disease 2019 (COVID-19) known case found in Wuhan, China in 2019, the pandemic has already lasted two years.[1] The pandemic influences people's life a lot that they cannot have the same lifestyle as before. There are many things that make people's life become inconvenient. For example, people have to wear masks inside rooms and keep safe to not have large gatherings. Also, in some government agencies, people need to make an appointment if they would like to attend. They may be forgetting to take masks or not on an appointment, so these things will both make people miss out on the thing they have to do. At the same time, the pandemic also influences people's social contact. In the most serious period of the pandemic, it is better for people to stay at home, so they cannot hang out with their friends a lot. Also, people meet with wearing masks. They cannot see others' full faces. If they are new friends after the pandemic, they will even be difficult to find each other without masks. These are both things which bring some big changes to people. Until now, the pandemic is better than years ago, but people still need to take care of themselves to be safe. Although people have already been conditioned to the pandemic, compared with the life before the pandemic, it really makes people's lives different.
Moreover, college students, they also affected by the pandemic. The study style changed a lot that the inperson classes change to be the zoom classes or even asynchronous online classes. Students cannot meet their professor or classmate with the change of the way of class. These limits students meet professors face-to-face for asking questions, and they cannot study with a classmate in the same class. Also, there are some laboratories canceled so students lose the chance to have these kinds of courses to improve themselves. Studying is one of the most important things for college students. The sudden change of the way for classes causes a big change of study style, so this may make college students feel bad or anxious. Therefore, the mental health of college students should be concerned since people should make sure that college students all adapt well to sudden changes in learning styles. It is important to focus on not only college students' body health but also their mental health during the pandemic.

There are few studies in the area of college students' mental health. In Xiaomei et al.'s studies in the mental health of college students, there is a large number of college students that $71.26 \%$ of students report that the level of stress or anxiety increases during the pandemic.[2] And even many students of $48.14 \%$ and $38.48 \%$ report the level of moderate-to-severe depression and stress.[2] The number of students who feel stress or anxiety is high. And there is more than one-third of students get a high level of depression and stress. It is 
easy to find from this study that the mental health of college students during the pandemic is really a problem that needs to be solved. At the same time, Changwon et al. did another study that reports that the afraid of health and academic grade, hard to concentrating, and disruption of sleep are both parts that make college students feel stress and anxiety.[3] People can see from these studies that mental health is the problem that will affect students in many different areas, like academics and sleep. Therefore, the author would like to find out the changes in the mental health of college students with the outbreak of the epidemic in terms of academics, sleep, and reflection on news reports, so that universities can understand what they need to do to help college students to go through this tough period. The author hypothesizes that college students' mental health changes to be worse during the pandemic in the area of worse academic and sleep and stronger response on news reports.

\section{METHOD}

\subsection{Participants}

The study included 727 participants $(\mathrm{N}=727)$ who are the person see the link of the survey online with 352 male students and 375 female students $(48.42 \%$ males and $51.58 \%$ females). Participants completed this survey voluntarily. They did not have to fill the survey out which means that they can ignore the message of the link of the survey, but they would also not get any reward after finishing the survey. The age of participants was from about 18-24 years old that they are undergraduate and graduate students. This study was focused on all the college students' mental health in the areas of academics and sleep, so the religion and race of students are not relevant.

\subsection{Materials}

Participants responded to the survey using 14 choice questions. The measurement of college students' mental health was by comparing the daily study hours and sleep hours during the pandemic with the number of hours per day before the pandemic. The decrease in the number of hours per day meant that college students' mental health was big impacted. And questions were about the classes ways, and sleep hours, and seeing news reports. The most kind of feeling participants report most could directly reflect the result.

\subsection{Procedure}

The survey would be posted on social media. Participants were volunteers and asked to complete the survey online by using phones or computers through the internet. This survey spent less than 5 minutes for participants to complete. Data were collected for analysis of the study after all the participants finished the survey. This study was the between-subjects design with participants should in the same range of age that they should be college students. And there are no conditions in this study. Collect and compare the daily study time and sleep time to find out which time has the biggest change. At the same time, through the influence and feeling of study on the pandemic and reflection on news reports, the relevant information is collected to understand the changes in the mental health of college students.

\subsection{Result}

This study was to find out that college students' mental health is worse than before caused by the pandemic. The daily study hours tend to decrease, but the daily sleep hours tend to increase. In the daily study hours in Figure 1, it is the negative distribution that regardless of how many hours they study per day, the number of participants who decrease 1-3 study hours per day is the largest. And in the influence and feeling of study on the pandemic in Figure 2, half of the participants with 50.62\% and $50.34 \%$ reported that the pandemic brings negative effects to them, and they have some negative feelings caused by the pandemic. 


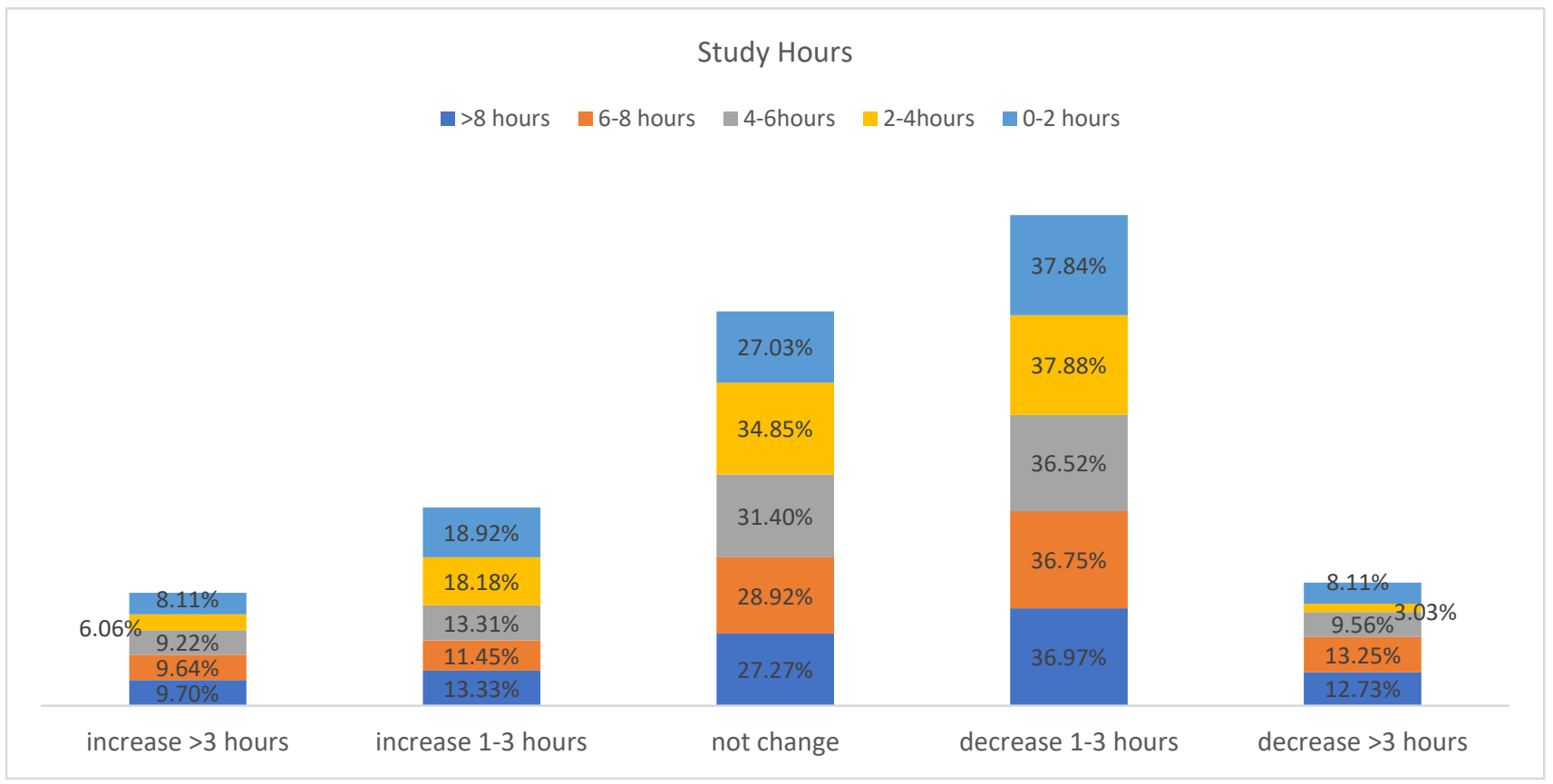

Figure 1 College Students' Study Hours per day.

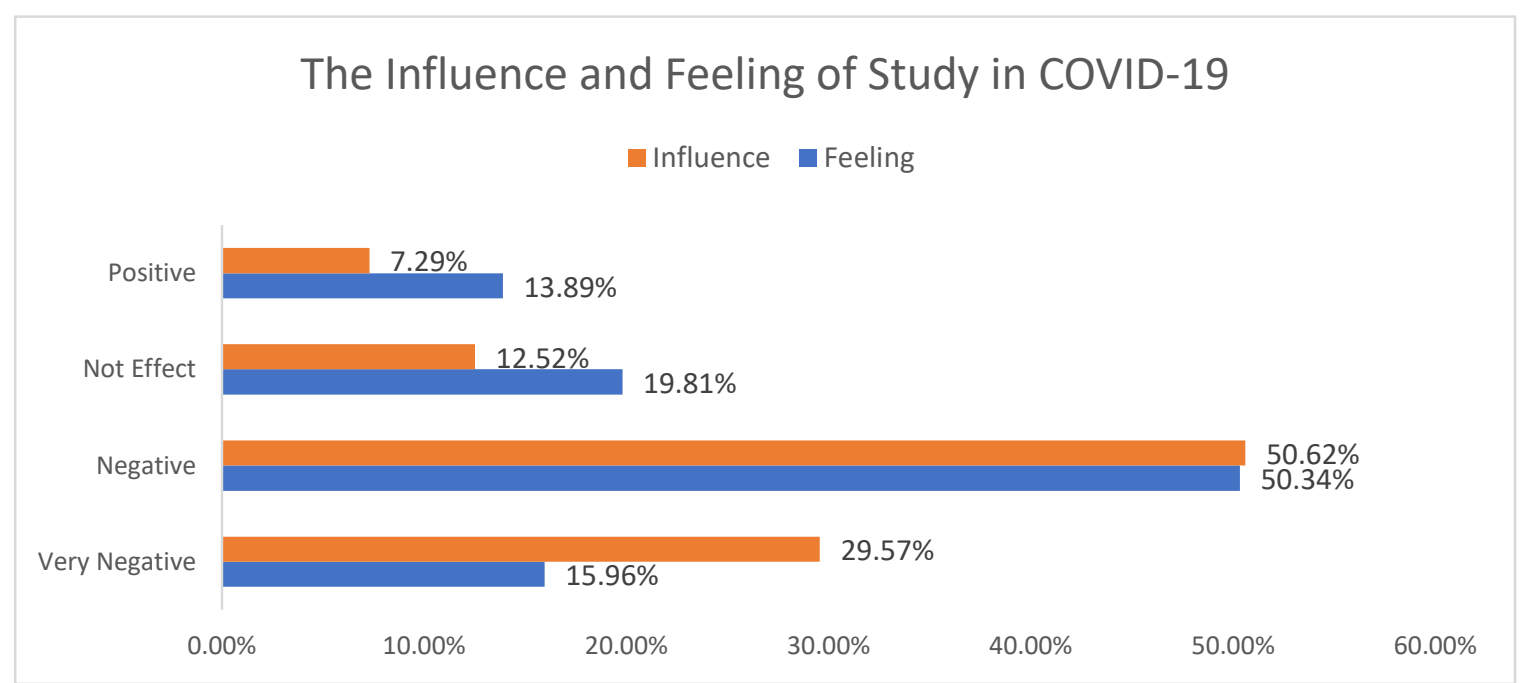

Figure 2 The Influence and Feeling of Study to the Pandemic that College Students Reported.

And in the daily sleep hours in Figure 3, it is close to the normal distribution that the number of participants who do not change sleep hours per day is the largest, but the number of participants who increase 1-2 sleep hours per day is also large which is close to the number in "no change". Also, in the effects on news reports in Figure 4,
$37.14 \%$ of participants reported that the news reports bring some negative effects that they would be worried about the situation of the pandemic and their body health. Also, there are $32.32 \%$ of participants reported that the news and reports would not affect them. 


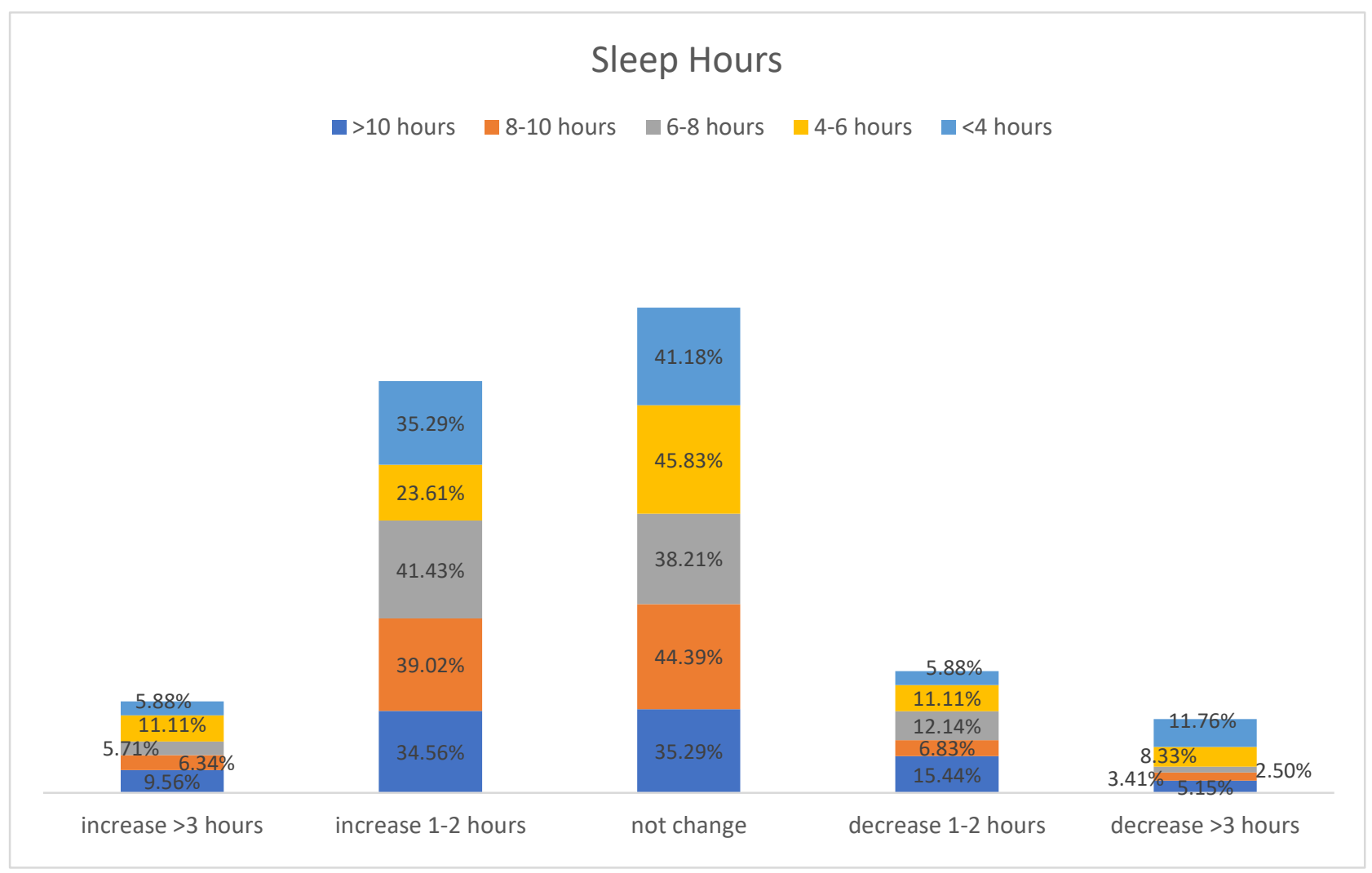

Figure 3 College Students' Sleep Hours per day.

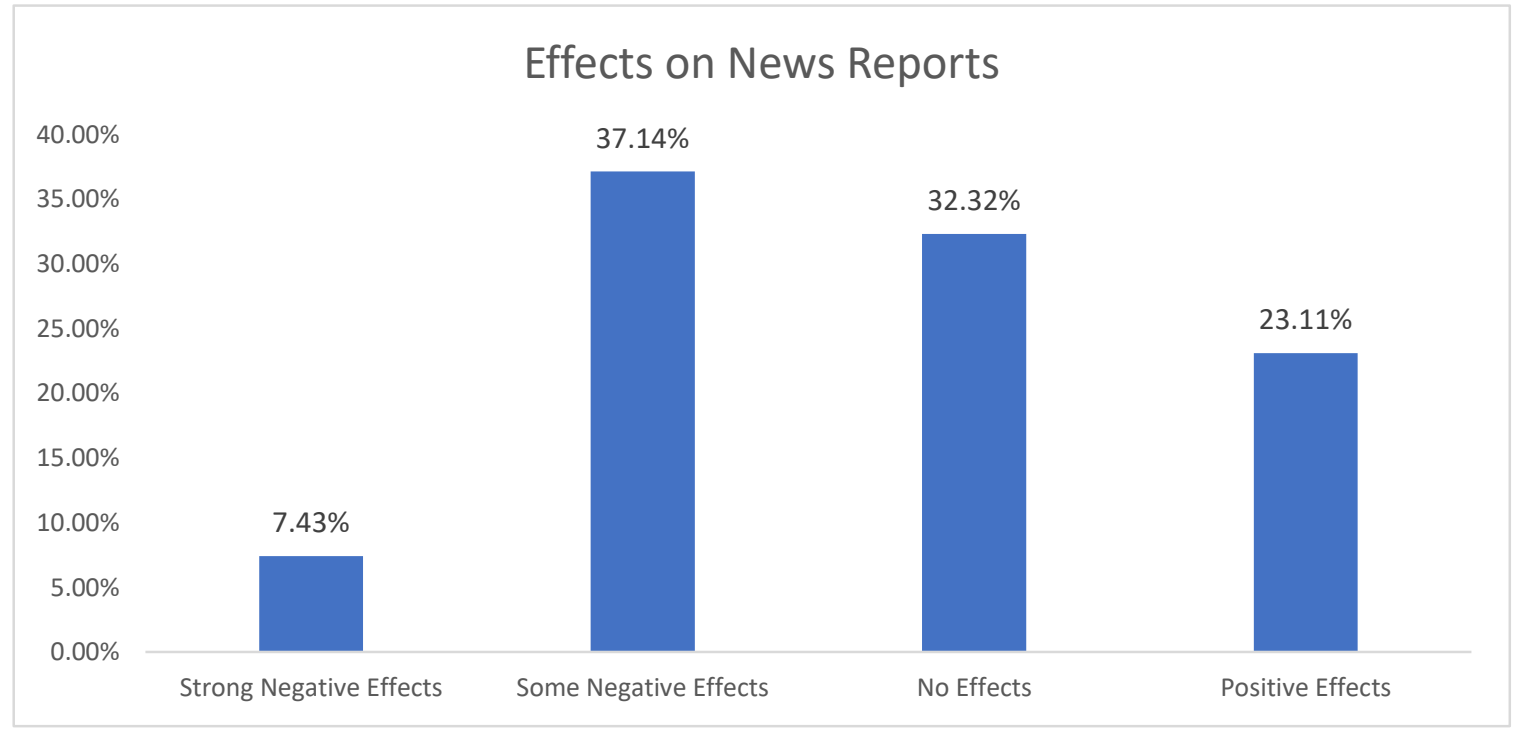

Figure 4 The Effects on News Reports to College Students during the Pandemic.

\section{DISCUSSION}

This study was about whether college students' mental health was affected by the pandemic in the areas of daily study hours, daily sleep hours, influence and feeling of study on the pandemic, and the effects on news reports. The measurement is the number of participants in different areas. And the author's hypothesis was that the pandemic causes the mental health of college students to be worse in the area of worse academic and sleep and stronger response on news reports. In this study, the academics tend to be worse than before that the study hours per day decrease 1-3 hours. Also, half of the participants get negative effects on the study during the pandemic. From these two results, participants thought that the pandemic had some negative effects on their study. This made them not in a good mood for study. And it made them feel worried and anxious. Under such 
emotions, it was difficult for them to study as they did before the pandemic. At the same time, the curve of study hours per day is a negative distribution. Under normal circumstances, the curve should be a normal distribution. Now medium has changed from "no change" to 1-3 hours less, which also shows that participants are really affected by the pandemic in terms of learning.

Moreover, sleep hours per day did not get worse in this study but tended to increase by $1-2$ hours. This is contrary to hypothesis of this paper, worrying about the pandemic does not lead to less sleep. And Grant's study also showed that the impact of the pandemic stress on college students' daily sleep hours was not entirely negative.[4] Because of the pandemic, college students have more time to sleep than before, and they can choose to wake up later instead of getting up early to attend classes. But the poorer quality of sleep among college students was due to their increased use of sleep medications, which actually causes their sleep efficiency to decrease.[4] At the same time, in the influence of reading news reports on college students, there are more than one-third of the participants $(37.14 \%)$ reported that they have some negative effects of news reports like worry. And slightly less than one-third of the participants $(32.32 \%)$ believed that news reports would not have an impact, so it can be concluded that news reports have little impact on their emotions. However, in Faheem et al.'s study, news headlines were emotional, and $52 \%$ of news headlines about the pandemic contain negative emotions, which can well explain that why $37.14 \%$ of participants said news reports had some negative impact on them.[5]

This study has some limitations in the selection of samples. The survey used in this study was posted on social media. Although most college students use social media, not all of them are willing to complete the survey. Participants who completed the survey would have similar characteristics that they are willing to help others, which makes the sample of participants not comprehensive enough because people with different personalities have different performances in the same thing.

In this study, it can be found that the pandemic has a great impact on college students' studies. Some students cannot adapt to the sudden change in class style, which leads to stress or anxiety. Meanwhile, all kinds of news reports about the pandemic from the media also affect the mood of college students. These negative emotions will affect not only the study status of college students but also their mental health. If these negative emotions are not relieved for a long time, more serious psychological problems will be formed. Therefore, college students should learn how to relieve their negative emotions during the special period of the pandemic. College psychological counseling centers should also provide more help to students, such as online psychological counseling, which is proved to be effective.[6] At the same time, society should also adjust negative news reports on the media to reduce the impact of news reports on college students' emotions.

\section{CONCLUSION}

In this study, it can be found that the pandemic has a great impact on college students' studies. Some students cannot adapt to the sudden change in class style, which leads to stress or anxiety. Meanwhile, all kinds of news reports about the pandemic from the media also affect the mood of college students. These negative emotions will affect not only the study status of college students but also their mental health. If these negative emotions are not relieved for a long time, more serious psychological problems will be formed. Therefore, college students should learn how to relieve their negative emotions during the special period of the pandemic. College psychological counseling centers should also provide more help to students, such as online psychological counseling, which is proved to be effective.[6] At the same time, society should also adjust negative news reports on the media to reduce the impact of news reports on college students' emotions.

\section{REFERENCES}

[1] Jeremy Page, Drew Hinshaw, and Betsy McKay (2021). In Hunt for Covid-19 Origin, Patient Zero Points to Second Wuhan Market - The man with the first confirmed infection of the new coronavirus told the WHO team that his parents had shopped there. The Wall Street Journal. https://www.wsj.com/articles/in-hunt-for-covid-19origin-patient-zero-points-to-second-wuhanmarket-11614335404

[2] Xiaomei Wang, Sudeep Hegde, Changwon Son, Bruce Keller, Alec Smith, and Farzan Sasangohar (2020). Investigating Mental Health of US College Students During the COVID-19 Pandemic: CrossSectional Survey Study. Journal of Medical Internet Research, 22(9): e22817. doi: 10.2196/22817

[3] Changwon Son, Sudeep Hegde, Alec Smith, Xiaomei Wang, and Farzan Sasangohar (2020). Effects of COVID-19 on College Students' Mental Health in the United States: Interview Survey Study. Journal of Medical Internet Research, 22(9): e21279. doi: $10.2196 / 21279$

[4] Grant Benham (2020). Stress and sleep in college students prior to and during the COVID-19 pandemic. Stress Health, 37(3): 504-515. doi: 10.1002/smi.3016

[5] Faheem Aslam, Tahir Mumtaz Awan, Jabir Hussain Syed, Aisha Kashif, and Mahwish Parveen (2020). Sentiments and emotions evoked by news headlines 
of coronavirus disease (COVID-19) outbreak. Humanities and Social Sciences Communications, 7, 23. doi: 10.1057/s41599-020-0523-3

[6] Gretchen A. Brenes, Suzanne C. Danhauer, Mary F. Lyles, Patricia E. Hogan, and Michael E. Miller (2015). Telephone-Delivered Cognitive Behavioral Therapy and Telephone-Delivered Nondirective Supportive Therapy for Rural Older Adults With Generalized Anxiety Disorder - A Randomized Clinical Trial. JAMA Psychiatry, 72(10): 10121020. doi:10.1001/jamapsychiatry.2015.1154 